\title{
Disclosure of Funding Sources and Conflicts of Interest in Phase III Surgical Trials: Survey of 10 General Surgery Journals
}

\author{
Michael G. Sarr • Andrew L. Warshaw
}

Published online: 23 May 2014

(C) Société Internationale de Chirurgie 2014

The last decade has shown burgeoning growth and the importance of industrial support for innovation and clinical trials that have advanced the practice of surgery. Quality clinical studies are expensive, as is the development of innovative technologies. The last decade has also shown only too clearly that some of those alliances have been abused by consequent bias of the outcomes or even for personal gain. As editors, we must be overly conscious of funding sources and especially situations of real or potential conflicts of interest. Editors, often informed by reviewers, must be on the look-out for malfeasance. However, as Tuech and colleagues have shown, we may miss some who stray from the righteous path. We thus fail in our responsibility to our readers to provide funding sources and how the "funding" was disbursed: for salary support of investigator, nurse, or study coordinator; materials/devices/medications used; data analysis; preparation of manuscript; unrestricted monetary "grants" often used for activities unrelated to the study at hand. Although we very closely and consciously review conflicts of interest that have been disclosed, there are others that were not disclosed, regardless of whether it was intentional. In those circumstances, neither we nor our readers are able to judge the validity of the reported data.

Tuech et al. [1] have asked the question, and we, the Editors-in-Chief of the journal, SURGERY, as well as the
Editor-in-Chief of the World Journal of Surgery, have heard them. We will address this topic at the next meeting of the Surgery Journal Editors Group (SJEG) this fall during the Clinical Congress of the American College of Surgeons. Each year the SJEG, which has representatives from many of the indexed surgery journals, meets to discuss topics of relevance to the field of medical publishing such as this important topic. It seems likely that the SJEG will adopt a general policy that all articles specify the source (and use) of funding and the presence or absence of pertinent disclosures of interest. The journal Surgery, which we co-edit, is adopting this policy immediately.

\section{Reference}

1. Tuech JJ, Bridoux V, Moutel G, et al (2014) Disclosure of funding sources and conflicts of interest in phase III surgical trials: survey of ten general surgery journals. World J Surg. doi:10.1007/s00268$014-2580-5$
M. G. Sarr ( $\bowtie)$

Department of Surgery, Mayo Clinic, 200 First Street SW,

Rochester, MN 55905, USA

e-mail: sarr.michael@mayo.edu

A. L. Warshaw

Massachusetts General Hospital, 55 Fruit Street, Boston,

MA 02114, USA 